\title{
THE ARCHITECTURE OF A SCHOOL SYSTEM ACCORDING TO THE THEORY OF DYNAMICAL SYSTEMS
}

\author{
Boris Aberšek, Janez Bregant
University of Maribor, Slovenia \\ Boris Aberšek, Janez Bregant
University of Maribor, Slovenia \\ E-mail: boris.abersek@uni-mb.si, janez.bregant@hotmail.com
}

a ni-mb.si, janez.bregant@hotmail.com

\begin{abstract}
From the experience of recent years it seems clear that the existing educational system, as a whole, is perceived as an ailing system that fails to meet the needs of a major portion of the society it serves. Every aspect of the educational process must be studied and reconsidered in the light of new and different societal expectations. In the last decades we started with one school reform after the other, but it looks now that these changes had no positive impact whatsoever. Even worse, the school system was damaged afterwards.

In this paper we will explore some possibilities how to improve it without facing these consequences. The main idea is, as a result of our latest research, that mathematical methods for describing and simulating could be very useful for predicting and simulating school systems without using a long term and complex empirical experimentation. The paper introduces the correlation between the dynamical mathematical calculus and the educational school system and elaborates to some extent the basic idea of using the former to predict the latter.
\end{abstract}

Key words: architecture, mathematical modelling, school system, theory of dynamical system.

\section{Introduction}

We talk a lot about quality and excellence in regular life and also in education (Aberšek, 2000). This immediately brings up a question what is meant by quality and excellence. Webster's New World Dictionary of the American Language defines quality as »the degree of excellence which a thing possesses « and excellence as »the fact or condition of excelling; superiority; surpassing goodness, merit«. (Guralnik, 1987) These definitions of quality and excellence imply that there is a direct link between quality and being the best at what you do regardless of what it is that you do. Quality improvement requires a change in attitude, and a development of new philosophy and new concepts. These concepts are simple but the practice of quality improvement is far from being easy.

The pressures for a reform of a school system that began in the 1980s and continued till today are different in intensity and duration from previous calls for a change. During the early 1980s educators experienced a wave of reforms that demanded from teachers and administrators to do more of what they had been doing and to do it better. These reforms continue at the university level with the so called "Bologna". The main problem of the reform is that is particular and as a rule non-comprehensive. Moreover it is structured and organized to meet mostly the needs of an age and society that no longer exist. The school system must be restructured and reorganized to meet different needs of the society at the beginning of the twenty-first century.

School educational systems on the threshold of the new millennium all over the Europe are experiencing radical changes. Deliberation, which generates these changes, is mostly oriented into the balancing act of which competences (capabilities) an educational system 
PROBLEMS

OF EDUCATION

IN THE $21^{\text {st }}$ CENTURY Volume 46, 2012

should develop with students in order to secure a successful performance of their expected roles during their lives and create their own prosperity. In this context it is exceedingly important to see school system aims as global as possible (and not as it happened with a previous renovation where they were local or subjective). We have to think about a correlation of knowledge among humanities, social sciences, natural sciences and technical fields and their role (dimension) at forming the entire personality for a future growth. It is not possible to deny that these disciplines and their techniques are inseparable connected: things get their practicability value (i.e. become logical) only in the field of application. Natural science knowledge gets its meaning in the application (of techniques and technologies) and therefore gets its market value which, in turn, leads to a rise of a social prosperity. That, however, reflexively generates new impetus of the society: art, culture, humanism... The circle is joined or even better: a vertical spiral is released. (Aberšek, 2008)

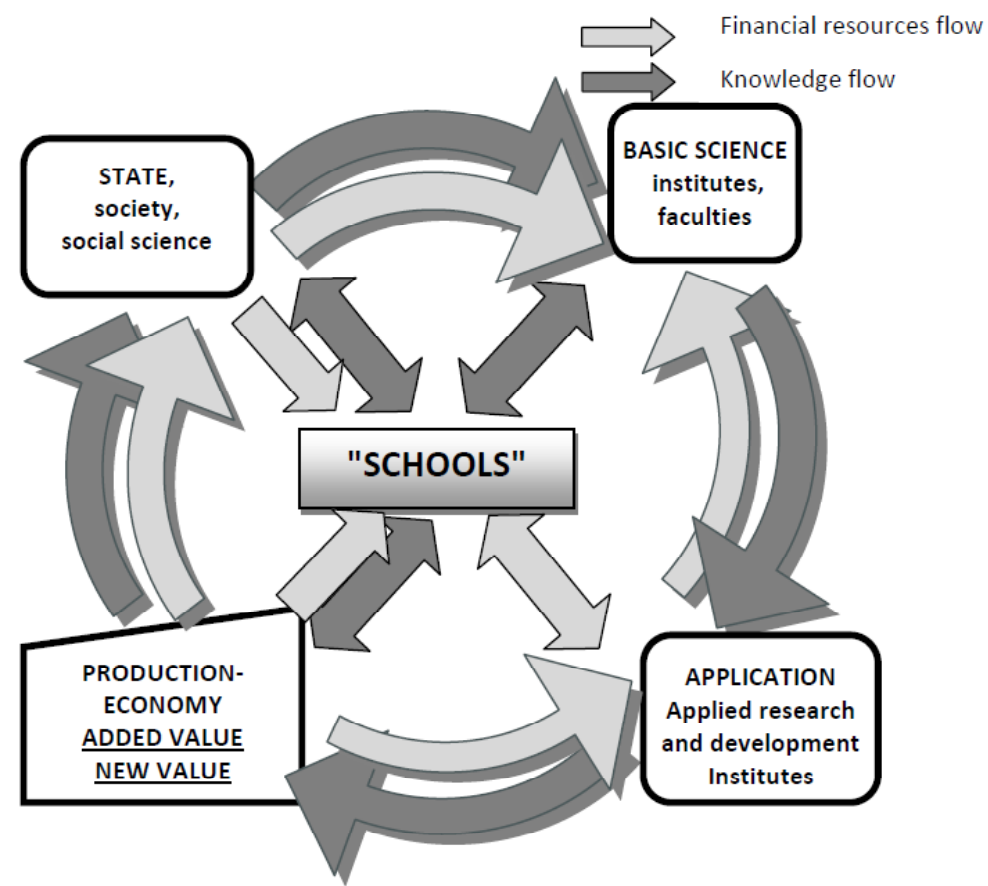

Figure 1: Social developmental circle (Aberšek, 2008).

To tackle the problem as a whole we have to be aware that the school system is built from the bottom up and is inseparable integrative: it connects kindergartens, primary schools, secondary schools and universities in the lifetime learning system, according to Figure 2. Every change of its individual segment has a direct influence on all of its other elements. With changes of an individual segment we achieve time connected changes and different intensity of them. Primary school changes generate long-term, entire and larger changes: their results will be shown in our economy, i.e. in the labour market, in years $2030-(9$ years of a primary school +4 years of a secondary school +6 years or more of a tertiary education); secondary school changes generate medium-term, larger changes: their consequences will be shown in our economy, i.e. in the labour market after the year 2020 or 2025; university level changes are short-term and non-systematic: for this reason we can not stipulate that they will fulfil local or even global demands. Their results will be shown over the year 2015 or 2020; in service training satisfies current, short-term needs and is being already by its definition non-systematic and designed for a particular user ,in the present" moment. 


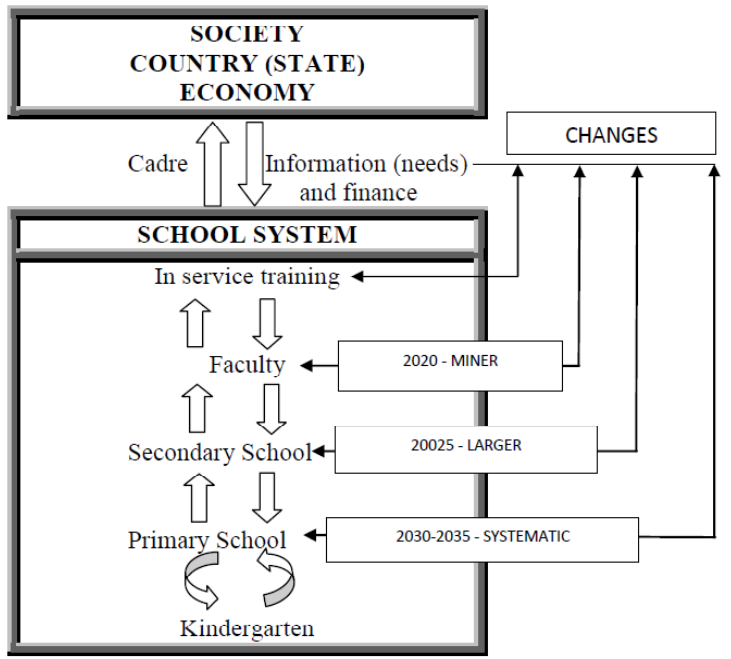

Figure 2: Strategic development of human resources.

\section{Methodology of Research}

Our idea is theoretical and chiefly connected with researching possibilities of developing a methodology compared to the classical empirical way of introducing school reforms. The alternative methodology is based on the Heimann (1976) description of the school system which will be transformed into the mathematical model. With such a model is (will be) possible to simulate how some changes influence the school system as a whole.

\section{Architecture and School System}

If we want to continue with our premise, i.e. that we can solve the problems of a changing school system in a soft and reliable way, we must first answer the following questions: how the school system looks like and how can we non-empirically predict the results of the changes. We must define its architecture and thereby take into account that a school system is a dynamical system.

\section{Architecture}

The architecture is both, the process as well as a product, of planning, designing and constructing. It is a medium of a cultural expression displayed using a specific set of principles. In the contemporary world the word architecture also gets many other meanings. For example, Newell introduced the term 'cognitive architecture' into cognitive science by an analogy with computer architecture (Bell, Newell, 1971); and a computer architecture was earlier introduced into a computer science by an analogy with the architecture of buildings (Brooks, 1962). The architecture is the art of specifying the structure of the building at a level of an abstraction sufficient to assure that the builder will achieve the function desired by the user (Anderson, 2007) This seems to be the idea that Brooks had in mind as the following passage shows: "Computer architecture, like other architecture, is the art of determining the needs of the user of a structure and then design to meet those needs as effectively as possible within economic and technological constrains" (Brooks, 1962: 5). Figure 3 represents an analogy between different types of architectures. 
PROBLEMS

OF EDUCATION

IN THE $21^{\text {st }}$ CENTURY

Volume 46,2012

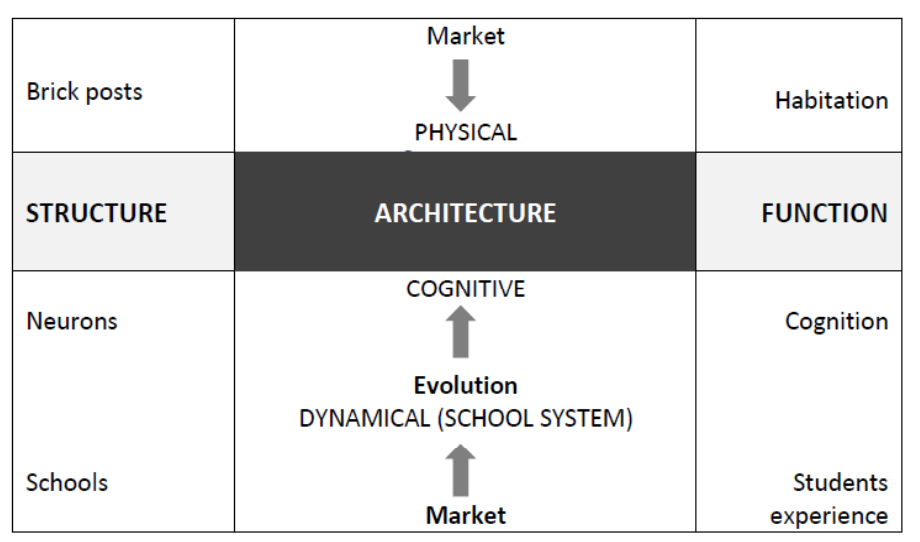

Figure 3: Analogy between different architectures.

In this paper our attention is pointed only to the last architecture, i.e. to the architecture of the dynamical model of the school system.

\section{Theory of Dynamical Systems}

In the broadest sense a dynamical system is any system that evolves over time in a law-governed way. The solar system is a dynamical system and so are dynamical systems its subsystems, for example, a human system or in our case a school system. Dynamical models typically track the evolving relationship between small numbers of quantities that change over time. They do this using calculus and differential or difference equations. The difference equation allows us to model the evaluation of a system that changes in discrete steps. So, for example, we might use the difference equation to model how the size of a biological population changes over time thereby each step being, for example, a year. The differential equation, in contrast, allows us to model quantities that changes continuously, such as the acceleration of a falling object (Bermudez, 2011, Kurzweil, 2005).

One of the basic theoretical ideas in a dynamical system modelling is the idea of the state space. The state space of a dynamical system is a geometric way of thinking about all the possible states that system can be in. The state space has as many different dimensions (independent or dependent variables) as it has quantities that vary independently of each other. Any state of the dynamical system will involve the system having a particular value in each dimension. So we can uniquely identify the state of the system in terms of a particular set of coordinates in the system state space. One of the basic aims of the dynamical systems modelling is to write equations governing the evaluation of the system that is, governing the different possible trajectories that the system can take through the state space depending upon where the system starts (i.e. the systems initial condition) (Bermudez, 2011).

For modelling the school system either difference or differential equations can be used: we can collect data about the changes once per year, which is more convenient but less accurate, or we model the changes in the school system as being a continuous process (Aberšek, 2004a).

\section{Structural and Factor Analysis}

The main problems of the mathematical modelling of systems are twofold: how to determine system's initial and boundary conditions and how to find out which equation will describe the school system the most accurately and reliably. We can solve the problems by using the following two powerful tools, that is, the structural and factor analysis. 
The structural analysis is the determination of the effects of loads on physical structures and their components. Structures subject to this type of analysis include all that must withstand loads, such as buildings, bridges, machinery, prostheses, biological tissue and also social systems. The structural analysis incorporates the fields of applied mechanics, materials science and applied mathematics to compute a structure's influence factor and stability of the system. The results of the analysis are used to verify a structure's fitness for use, often saving physical (experimental) tests.

The factor analysis is a statistical method used to describe a variability among observed, correlated variables in terms of a potentially lower number of unobserved variables called factors. In other words, it is possible, for example, that variations in three or four observed variables mainly reflect the variations in fewer unobserved variables. The factor analysis searches for such joint variations in response to unobserved latent variables. The observed variables are modeled as linear combinations of the potential factors plus "error" terms. The information gained about the interdependencies between observed variables can be used later to reduce the set of variables in the dataset. Computationally this technique is equivalent to a low rank approximation of the matrix of observed variables. The factor analysis originated in psychometrics, and is used in behavioral sciences, social sciences, marketing, product management, operations research, and other applied sciences that deal with large quantities of data (Byrne, 2006).

Both analyses are also extremely useful also in social science researches. Heimann (1976) use them to find out factors which influence the teaching/learning process. According to Figure 4 the school system can be described by the same factors.

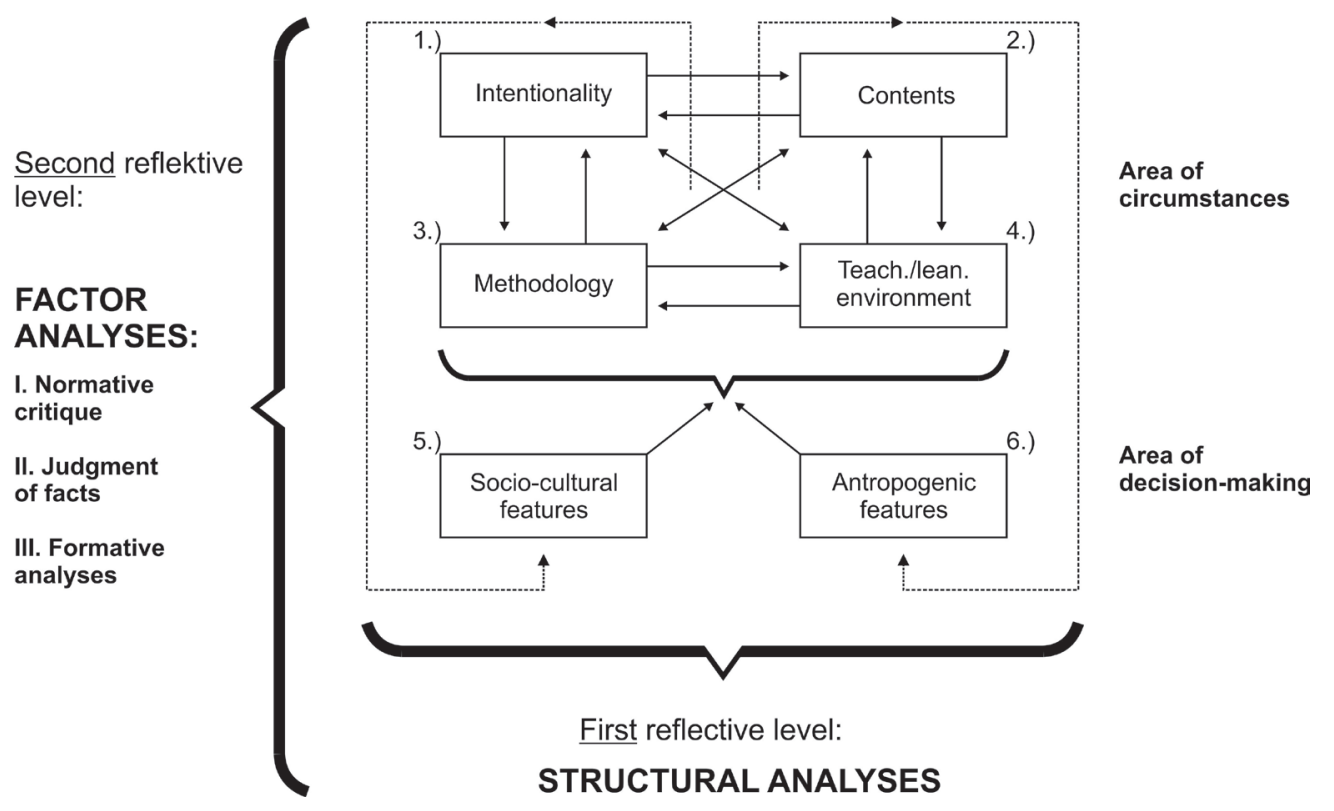

Figure 4: Structure and factor analysis (Heimann, 1976).

A short symbolical description of the problem solving procedure is shown in Figure 5. After step 1, which is defining the school system according to Figure 4, the physical and then the mathematical model must be determined. 
PROBLEMS

OF EDUCATION

IN THE $21^{\text {st }}$ CENTURY

Volume 46,2012

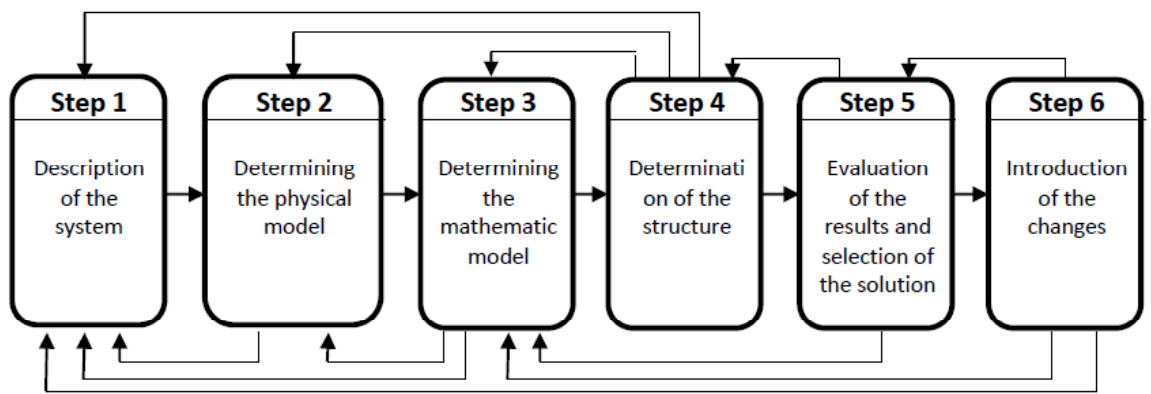

Figure 5: Problem solving procedure.

The concept of the modal analyses could be used if the continuous non-homogeneous structure could be written in the form of a physical dynamical system with more degree of freedom. According to Heimann (1976) and from Figure 4 we can imply that we have the dynamical system with four degrees of freedom: intentions, contents, methodology and teaching/learning environment. Symbolically is such a physical system shown in Figure 6.

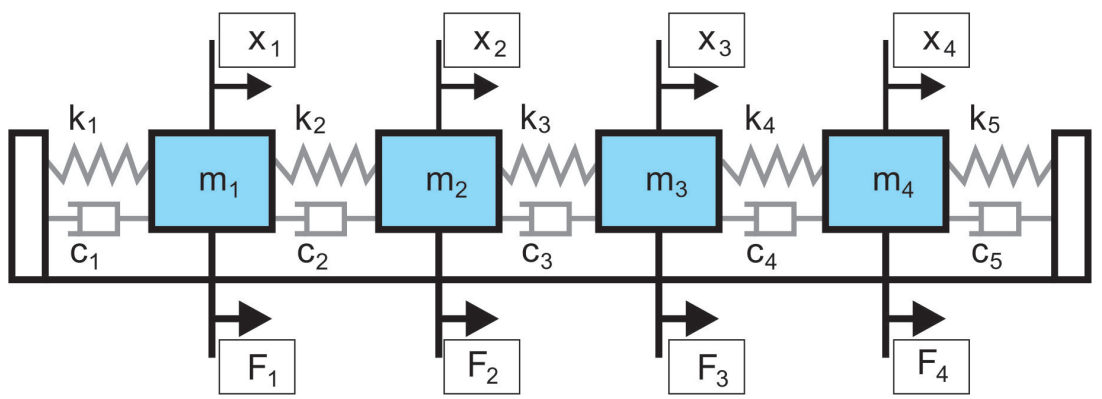

Figure 6: System with four degrees of freedom.

The mathematical modelling which is the next phase after the formation of a physical model is writing the physical system in the form of equation of motion. This equation in the most general form represents a non-conservative, nonlinear second order differential equation (Aberšek, 2004b). In matrix form:

$\mathbf{M} \ddot{x}+\mathbf{C} \dot{x}+\mathbf{K} x=\mathbf{F}(t)$

On the basis of this we can state the school system in terms of equations, i.e. in terms of dynamical systems:

where:

$$
\mathbf{I} \ddot{\Theta}+\mathbf{D} \dot{\Theta}+(\mathbf{K}+\mathbf{N}) \Theta=\mathbf{h}(\mathrm{t})+\mathbf{f}(\mathrm{t} \dot{\Theta}, \Theta)
$$

$$
\begin{array}{ll}
\mathbf{I}=\operatorname{diag}\left[\mathrm{I}_{1}, \mathrm{I}_{2}, \ldots, \mathrm{I}_{\mathrm{n}}\right] & \text { - matrix of intention } \\
\mathbf{D}=\operatorname{diag}\left[\mathrm{D}_{1}, \mathrm{D}_{2}, \ldots . \mathrm{D}_{\mathrm{n}}\right] & - \text { - matrix of methods } \\
\Theta=\left(\Theta_{1}, \Theta_{2}, \ldots \Theta_{\mathrm{n}}\right) & \text { - vector of changes } \\
\mathbf{K}=\operatorname{diag}\left[\mathrm{K}_{1}, \mathrm{~K}_{2}, \ldots, \mathrm{K}_{\mathrm{n}}\right] & \text { - matrix of contents } \\
\mathbf{N}=\operatorname{diag}\left[\mathrm{N}_{1}, \mathrm{~N}_{2}, \ldots, \mathrm{N}_{\mathrm{n}}\right] & \text { - vector of teaching and learning environments }
\end{array}
$$


$\mathbf{f}(\mathrm{t}, \dot{\Theta}, \Theta) \quad$ - vector of socio-cultural characteristics

h $\quad(\mathrm{t}) \quad$ - anthropology characteristics

In general, depending on the number of elements of the school system we obtain the number of differential equations of the second order, which is in most simplified version of the algorithm solved by the conventional method of Runge Kutta. For more sophisticated and realistic results the use of the theory of chaos is more appropriate. The results of the calculation are predictions which indicate the development and changes in the school system according to changes of input factors (the initial and boundary condition) (Pearl, 1983, Aberšek, 2004b).

\section{Conclusion}

The paper looks at some of the possibilities opened up by a more recent and non-orthodox way of exploring the school system by the use of the mathematical modelling and simulating. It begins by examining what are the influencing factors in this process and points out that for the first approximation the Heimann (1976) theoretical work is good enough. On the basis of this it shows that the mathematical and conceptual tools of the dynamical system theory could be used. These models exploit the time-sensitivity that dynamical models offer in order to show how a system evolves over time as a function of changes of systems variables, that is, intentions, contents, methodology and teaching/learning environment.

The introduced research is in the early phase, approx. at step 3 to 4 in Figure 5. However, it is important to point out and prove that there are tools to build up a reliable and accurate simulating model which will help us to predict consequences of a reformation of the school system. On the basis of this data anyone will be able to make a cost/benefit analysis of a potential reform in advance and minimize or eliminate fatal results of wrong decisions.

Like all powerful tools this one could be very useful but also very dangerous. Without a carefully designed experience and extensive testing these systems could easily result in unwanted outcomes. Despite the promise of the early efforts the best approaches to designing and simulating the model of a school system are still a subject of the research and debate. We have to point out, though, that the dynamical system theory offers fresh and distinctive perspectives as well as a long and thorny way to the finish line, or as the old Latin phrase says: Per aspera ad astra. ${ }^{1}$

\section{References}

Aberšek, B. (2008). Future for science and engineering education. Problems of Education in the 21st Century, 6, 9-17.

Aberšek, B., Popov, V. (2004a). Intelligent tutoring system for training in design and manufacturing. Advanced Engineering Software, 35, 461-471.

Aberšek, B. (2004b). How gears break. Boston, Southampton, WIT Press.

Aberšek, B. (2000). Project Tempus: Quality assurance at the University of Maribor. University Journal, 7, 29-30.

Anderson, J. R. (2007). How Can the Human Mind Occur in the Physical Universe. Oxford, Oxford University Press.

Bell, C. G, Newell, A. (1971). Computer structures: Readings and Examples. New York, McGraw-Hill.

1 Which means either "Through hardships to the stars", "A rough road leads to the stars" or "To the stars through difficulties". 
PROBLEMS

OF EDUCATION

IN THE $21^{\text {st }}$ CENTURY

Volume 46, 2012

14 Brooks, F. P. (1962). Arhitectural philosophy. In Buchholz, W. (Ed.), Planning a Computer System. McGraw-Hill, New York.

Bermúdez, J. J. (2010). Cognitive Science. Cambridge, Cambridge University Press.

Byrne, B. M. (2006). Structural equation modeling with EQS: Basic concepts, applications, and programming (2nd Ed.). Mahwah: Erlbaum

Guralnik, D. B. (Ed.) (1987). Webster's new world dictionary of the American language. Warner Books.

Heimann, P. (1976). Didaktik als Unterrichtswissenschaft. Stuttgart, Klett.

Kurzweil, R. (2005). The Singularity is Near. New York, Viking Press.

Pearl, J. (1983). Heuristics: Intelligent Search Strategies for Computer Problem Solving. New York, Addison-Wesley.

Advised by Vincentas Lamanauskas, University of Siauliai, Liathuania

Received: May 10, 2012

Accepted: July 20, 2012
Boris Aberšek

PhD, Professor, Head of the Department of Technical Education University of Maribor, Faculty of Natural Sciences and Mathematics, Koroška 160, 2000 Maribor, Slovenia.

E-mail: boris.abersek@uni-mb.si

Website: http://tehnika.fnm.uni-mb.si
$\mathrm{PhD}$, Associate Professor, Head of the Department of Philosophy University of Maribor, Faculty of Arts, Koroška160, 2000 Maribor, Slovenia. E-mail: janez.bregant@hotmail.com 